\title{
Internationalization Of Higher Education: A Reflection On Success And Failures Among Foreign Universities In The United Arab Emirates
}

\author{
Sepideh Mahani, Higher Colleges of Technology, Abu Dhabi Women's College, United Arab Emirates
} Arman Molki, The Petroleum Institute, United Arab Emirates

\begin{abstract}
Globalization has affected many sectors of the society, including higher education. In the current global economy, higher education institutions face numerous challenges. Factors such as the increasing international competition, achieving higher ranking among global universities, and the pursuit of creating world-class institutions has had a significant impact on higher education institutions. While universities respond to these challenges differently, some higher education institutions are increasingly moving toward the internationalization of their campuses. Internationalization of higher education programs includes branch campuses, cross border collaborative programs, exchange of international students, and establishment of English-medium programs and degrees. Over the past decade, the United Arab Emirates (UAE) has been on the receiving line of this phenomena. Internationalization of higher education has greatly affected the UAE as it continues to strive toward becoming a leading education hub in the Middle East. Until recently, the goal of the UAE has been to make higher education accessible to all students within the UAE by providing them with quality learning resources. However, over the past several years, in addition to providing its citizens with quality education, the country is working toward establishing itself as a world-class regional education hub through inviting prominent universities to set up campuses in the country. This paper examines the current trends in internationalization of higher education and analyzes the recent successes and some unanticipated outcomes of this phenomenon in the UAE.
\end{abstract}

Keywords: globalization; internationalization; higher education; United Arab Emirates; Middle East

\section{INTRODUCTION}

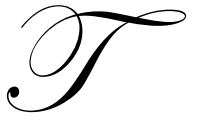

he efforts of the United Arab Emirates (UAE) to improve its higher education system through collaboration with Western universities represent a current trend in the higher education sector. For decades, countries such as Singapore, Kingdom of Saudi Arabia, and South Korea have all engaged in similar collaborations in an effort to improve the quality of the higher education institutions in their countries. However, globalization of higher education is not a trend exclusive to recent years. In the $19^{\text {th }}$ century a group of American students travelling to Germany had the opportunity to attend German universities. At the time, the German higher education system was the first to combine research and teaching activities. This and latter trips resulted in the establishment of American universities based on the German model, such as Johns Hopkins University and the University of Chicago. Today, the American higher education system has not only perfected the concept of renowned universities, but a system such as the German higher education system that once used to be a role model is now looking to the competitive culture of American universities for inspirations to restore it's struggling higher-education system (Wildavsky, 2010). Over a century later German students are traveling to the United States to gain access to a better education. For example, during the 2008-2009 academic year, Germany was among the top 10 countries having the highest number of foreign students studying in the USA (Almanac of Higher 
Education, 2010). This indicates the ever-changing nature of higher education and the difficulty of making longterm predictions about the growing global higher education market.

Globalization has affected many higher education systems over the past two decades. Many students now seek oversees education in order to be well prepared for the global market. Studying oversees has become a new trend; nearly three million students worldwide now study outside their home countries, a 57\% increase in just the past decade (Wildavsky, 2010). The number of international branch campuses has also grown dramatically, with more than 160 around the world. Countries worldwide are becoming aware of the economic benefits of educational institutions and are working hard to improve their enrollment rates (Wildavsky, 2010). It is estimated that the number of globally mobile students will nearly triple to eight million by 2025. India and China are said to continue to be the world's leading exporters of students, although China has started to import students from other Asian countries (Wildavsky, 2010). International research collaborations amongst universities are another growing trend, and have almost doubled in the past two decades. Such international collaborative work in education ensures that academic progress in one part of the world could result in advancements and growth in another part of the world. Allowing people and knowledge to freely move beyond campus walls is constructive to all parties involved.

\section{EDUCATION STRUCTURE IN THE UAE}

The higher education system in the United Arab Emirates has undergone substantial change since the establishment of the country almost 40 years ago. As a country, the UAE was established in 1971 through a union between the rulers of the seven emirates of Dubai, Abu Dhabi, Sharjah, Ajman, Umm Al Quwain, Ras Al Khimah, and Fujairah, with Abu Dhabi being the capital city. While Dubai's economy is mainly generated through tourism and the financial sector, Abu Dhabi's economy relies largely on its oil revenues. In 2007, Abu Dhabi's contribution to the UAE's GDP was almost 55\%, while Dubai contributed just over 30\%, and the remaining $15 \%$ was contributed from the other five Emirates (Bitar, 2009).

At the time of the country's establishment in 1971, a total of 74 schools existed throughout the seven emirates, and those who chose to pursue a higher education had to travel oversees. In 1977 the United Arab Emirates University (UAEU) was established as the first university in the UAE, followed by Higher Colleges of Technology in 1988, which was initially a vocational school but today offers both graduate and postgraduate degrees across 17 campuses. Zayed University was the third university that was founded by the federal government in 1998. Today, Zayed University has expanded its campuses from Abu Dhabi to Dubai and is planning to open a state-of-the-art flagship campus in September 2011. According to Zayed University's provost, Dr. Daniel Johnson, the university forecasts that their enrollment would increase from the current 4,820 to 9,000 in 2014, reflecting an intense increase in the number of Emiratis reaching university age (Bardsley, 2009).

Article 23 of the constitution of the UAE recognizes the important role of education in the development of the nation, and therefore guarantees free education to all Emiratis at all levels. Hence, all Emirati students who graduate from high school are entitled to attend one of the three federal higher education institutions (Wilkins, 2010). Aside from federal higher education institutions, a large number of higher education institutions exist in the UAE. Private universities in the UAE are either owned locally or they are extensions of and managed by foreign institutions. One of such institutions is the American University of Sharjah, which was established in 1997 by the ruler of Sharjah. In 1997 the Dubai Chamber of Commerce and Industry established the Dubai University, and in 2006 the Abu Dhabi Education Council established Paris-Sorbonne University, which is locally managed (Wilkins, 2010).

Nearly 40 years after the establishment of the United Arab Emirates, the country is moving towards becoming a competitor to countries such as China, Singapore, and the Kingdom of Saudi Arabia who have each invested considerably in establishing top-tier research universities. The efforts of the UAE in investing in its higher education system will most likely continue given its wealth and the vision of its leaders. Currently there are 73 higher education institutions licensed by the UAE Commission for Academic Accreditation (CAA), of which 28 institutions are based in Abu Dhabi, 28 institutions based in Dubai, and the remaining 17 institutions are located in the other emirates (Commission for Academic Accreditation, 2011). It should be noted that not all institutions of higher education are accredited by the CAA; for example, in the emirate of Dubai, 28 non-accredited institutions of 
higher education are in operation (The Higher Education Landscape, 2010). These intuitions are located in one of 5 Free Zones and are instead required to undergo the University and Quality Assurance International Board (UQAIB) quality assurance process established by the Dubai Knowledge and Human Development Authority (KHDA) which oversees the quality of higher education in institutions in the Free Zones. Many of UAE's higher education institutions are international branch campuses, such as Herriot Watt University, University of Wollongong, Middlesex University, University of Pune, and New York University, Abu Dhabi. What remains to be seen is the long-term academic and economic results of these institutions.

Some critics have suggested that the number of colleges and universities in the UAE exceeds the current demand (Moussly, 2010). According to Lewin (2008), nearly two-thirds of the private institutions in the UAE were established after 2005. The speed at which universities have been established in the UAE has been referred to as educational gold rush. Initially these foreign institutions were established to cater to the Emirati students, and the children of the expatriate community who do not wish to leave the UAE and are not permitted to study in the government-financed universities that are reserved for Emirati nationals. International branch campuses in the UAE do not all share the same motives; while perhaps some establish campuses as a quick way of generating revenues, others do so to enhance research and knowledge collaboration.

\section{SUCCESS \& FAILURES}

Over the past five years many universities have opened their doors in the UAE, with some succeeding while others failing to deliver results either academically or economically. Government officials in the UAE continue to allow international institutions to establish campuses across the seven Emirates, with the intention to not only serve the local population, but to establish the country as a thriving regional educational hub similar to Asian countries such as Singapore and Malaysia. According to Becker (2009), between 2006-2009, 49 international branch campuses started their operations in the UAE, most of which were American, Australian and British universities. A research study indicated that $62 \%$ of students in the UAE studying in UK-based institutions stated that the UK offered the best higher education in the world (Wilkins, 2010). Hence, with such positive reputation amongst students in the UAE, one can assume that these international campuses should not have difficulty attracting students. However, over the years, not all international universities have been successful in the UAE, as some have had to terminate their operations soon after starting.

\section{George Mason University}

In 2009, less than three years after it opened its campus in the Emirates of Ras Al Khaimah, George Mason University (GMU), an American university based in the state of Virginia, had to close its doors due to low enrollment rates. Even though the university enrolled 180 students, it was unable to meet its recruitment target (Bardsley, 2008). Upon closure of its campus all students enrolled at GMU-RAK were provided with the opportunity to study at George Mason's Virginia campuses (GMU-RAK, n.d.). At the time of closure, several UAE institutions, including Michigan State University Dubai, American University in Dubai, Ajman University, and University of Sharjah expressed interest in GMU-RAK students by establishing a number of teach-out agreements. After closure of the university, the Crown Prince and Deputy Ruler of Ras Al Khaimah issued a decree creating the American University of Ras Al Khaimah.

\section{Michigan State University Dubai}

Michigan State University's branch campus in Dubai closed after a two-year effort to create a top-tier university. At the time of the campus' establishment, the institution hoped to enroll 400 students by its second year, however, the total number of their enrollment was 85. Michigan State University's president, Lou Anna K. Simon, stated that even though they offered the similar undergraduate program as their American campus and hoped to attract the same type of students, the university had to close its doors due to Dubai's financial meltdown which started few weeks after the branch opened its doors in the Dubai International Academic City due to low enrollment rates and lack of qualified students (Mills, 2010). Michigan State University was founded through the support of Dubai Holding; a company owned by the Dubai ruling family and founded on a $\$ 5$ million loan and grants. MSU's 5 year strategic plan meant that they had to attract between 100 to 200 undergraduate students for each incoming class 
in order to sustain the five academic programs they were offering. However, during the last months of its operation, it had become clear to administrators that the campus was not able to operate and survive with 85 students across five programs. Therefore, once the university applied to the UAE's National Research Foundation for funds, and was turned down, they reduced their tuition rates by $50 \%$ to students who were willing to transfer from other Dubaibased universities. Of the 220 students that applied, only 20 qualified academically. With only 20 students, MSU was unable to survive and applied for a $\$ 3.4$ million loan to Dubai Holding, which was declined and the university finally closed down (Mills, 2010).

While the Dubai financial meltdown had a negative impact on Michigan State University's success, its competitors claim that the institution's failure was due to high tuition rates and the absence of a local track record. The Dubai economic recession did cause some loss of jobs, but mainly amongst younger expatriates in their 20s and 30 s who worked in real-estate and construction, not the mid-level executives and older expatriates who have university age children. The Michigan States University's Dubai campus tuition was $\$ 16,000$, which was approximately 23\% higher than Heriot-Watt and Wollongong universities. Other universities such as the American University of Sharjah and the American University of Dubai have higher tuition, but they are able to attract a large number of students since they are full campuses offering a variety of academic programs and student service (Mills, 2010). One of the factors that caused the closure of Michigan State University in Dubai was the financial problems the institution was facing in its home campus in the United States. A decline in state revenues, programs cuts, escalating tuitions and frozen salaries, meant that the university couldn't sustain the struggling campus' operation in the Middle East (Mills, 2010).

\section{Indian University Of Pune}

The most recent failure amongst internationally branched universities has been the Indian University of Pune, which opened a branch campus in 2009 in the emirate of Ras Al Khaimah. Universities are keen to opening campuses in the Emirate of Ras Al Khaimah, because of the existence of an educational free zone in which institutions do not require accreditation from the Ministry of Higher Education and Scientific Research. The president of the institution, Mr. Shukat Mirza, blames its failure on lack of enrollment, and stated that they have faced difficulties attracting students since the university is located in Ras Al Khaimah, a less populated Emirate that does not offer the same lifestyle available to students in Abu Dhabi and Dubai (Swan, 2011).

\section{University Of Wollongong}

In the same year that Michigan State University closed down, the Australian University of Wollongong's Dubai branch had its highest enrollment since its establishment in the UAE. The University of Wollongong opened in Dubai in 1993 in a rented office building adjacent to an abandoned shopping complex, with only eight students. The university started operating without any grants or loans; however, it grew slowly as it depended on its tuitionfinanced budget. Today, it has 4,500 alumni and has moved to Knowledge Village an education complex. Currently the university enrolls 2,500 students (Mills, 2010).

\section{Heriot-Watt University}

Scotland's Heriot-Watt University is an example of a fast growing university in the UAE. The university started with 117 students in its first year and this number increased to 500 within three years. Today, after five years since its establishment, Herriot-Watts' Dubai campus student enrollment is 1,400. The university is currently working on constructing a 300,000 square foot campus that will accommodate up to 4,500 students (Mills, 2010).

\section{New York University, Abu Dhabi}

New York University, Abu Dhabi started in 2010 accepting 2.1\% of the 9,048 applicants who applied to the university. Of those accepted, almost four out of five chose to enroll in the university. Currently, NYU Abu Dhabi has 150 students from 39 countries around the world, who speak 43 languages among them. The average SAT score of the 150 students is above 700 on the verbal and math sections. Critics have wondered what motivates students from the United States to move across the world to the Middle East to attend a university. Perhaps 
NYUAD's attractive package plays a role in their decision. NYUAD's tuition, room, and board costs $\$ 62,000$, a cost that is covered entirely by the government of Abu Dhabi. Students are provided with comfortable living quarters in addition to a $\$ 2,000$ travel allowance allowing them to travel to their home country few times a year (Riley, 2010). Due to instabilities in the past three decades, the Middle East has not been a popular destination for students who pursue oversees education. Between 1987 and 1988, among the American students studying abroad approximately 5\% were studying in the Middle East; this number dropped to 1\% a decade later in 2007-2008 (Almanac of Higher Education, 2010), perhaps due to the political instability and wars in the region. However, with the establishment of an education hub and Western university campuses such as NYU, the number could significantly increase in the coming years. According to Mills (2010), NYU Abu Dhabi's goal is not merely to enhance education in the UAE but to help UAE become an educational hub by creating an intellectual center and academic elite in the Middle East where political and social freedoms are works in progress.

NYUAD is a project supported and funded by the government of Abu Dhabi who has invested millions of dollars into the development of the university, including a \$20 million grant to support three research projects on the campus in the sciences and humanities. The total number of research money available at NYUAD has not been made public, however, according to Mills (2010) eight additional major research projects are under review. In order to attract students, the university contacted guidance counselors at the top 800 high schools internationally and encouraged them to nominate their two best students to apply to NYU Abu Dhabi. In 2010, the university recruited 300 students from around the world and flew them to Abu Dhabi so they could tour the city and get a glimpse of what it would be like to live in the city (Mills, 2010).

According the United States Department of Education, there are currently 4,400 colleges and universities across the United States. Skeptics wonder what is motivating these students to travel and study in a country where they have most likely have never travelled to. According to Riley (2010), perhaps NYUAD is attracting students because it is a new venture and the idea is appealing to American high-school students, but Riley (2010) argues that the possibility exists that this shine and enthusiasm may start to wear off, and students may reconsider the four-year abroad, as opposed to many one-year abroad programs available to them. Of course there are many skeptics who predict the plan to recreate another NYU campus in a region where political freedom is limited will face numerous challenges and contradict the values and beliefs that NYU stands by. Universities operating in the region do not have control over the local laws and must respect and abide with all the regulations. Senior administrators at NYUAD perceive their limitations as challenges that could perhaps teach students what it means to be culturally sensitive in a global environment, and it will encourage them to find ways to develop relationships among people with whom they may disagree (Riley, 2010)

\section{Masdar Institute Of Science And Technology}

Another internationally affiliated university that opened in the UAE is the Masdar Institute of Sciene and Technology, which is affiliated with Massachusetts Institute of Technology. The assistant dean for research at Masdar states that the affiliation with MIT will provide people with the comfort that the institution is legitimate and reliable. As a post-graduate-only university, Masdar currently enrolls 92 students from 22 different countries and is planning to increase its student population to 800. Qualified students were accepted into the postgraduate program from around the world and are offered full tuition, accommodation, monthly stipend, personal computers, all text books, and travel reimbursements (Lindsey, 2011).

\section{THE FUTURE OF HIGHER EDUCATION IN THE UAE}

In 2010 Abu Dhabi Education Council announced that a reform strategy is being planned to restore what it described as an ineffective and uncoordinated education system. As part of the plan, the government plans to invest $\$ 1.3$ billion in the nation's higher education by 2018 . The aim of this strategic plan is to increase research and coordination amongst universities in the country. According to the report, due to the lack of research and coordination amongst the universities, the current system has been producing low-quality graduates whose skills are inadequate for the current competitive job market. According to the report, the current universities in the UAE rank poorly internationally with only one, the UAE University among the top 500 in the world. As part of the reform, the 
government intends to provide all the universities with incentives to seek international accreditation (Hirschfeld \& Baker, 2010).

\section{CONCLUSION}

As education institutions continue to expand beyond their flagship campuses, the trend of fast growing international campuses will most likely continue to grow. With the advancements in technology, today's university students have never been more connected with the world they live in, hence seeking a global education oversees will also continue to be a widespread trend among future generations. As one research estimates, the number of globally mobile students will nearly triple to eight million by 2025 (Wildavsky, 2010). Starting a university is an exciting endeavor, especially when it is in a foreign country. However, it requires more than passion, because the process involves hard work such as finding financial support, faculty members, administrators, students and a location to house the institution. It also involves dealing with a new culture and regulations and ensuring that the culture and the laws of the host country are respected. One of the most important issues that higher education institutions face while expanding beyond borders, is that they often find themselves at the intersection of new cultures and confusing regulations. In order for these institutions to be academically and economically successful, they must recognize the cultural and legal differences in the host country. Failure to comply with these cultural and legal differences could result in civil or criminal liability, culture clash, and an outraged host government. In order to prevent such problems, institutions must recognize and understand the host country's laws, regulations and cultural differences (Hirschfeld \& Baker, 2010). Perhaps the institutions that failed to deliver economically or academically in the UAE's education market, had not researched the UAE's educational needs and requirements in advance, or perhaps their over enthusiasm, lack of preparation and awareness about the local market, UAE's culture and regulations resulted in their closed doors.

\section{ABOUT THE AUTHORS}

Sepideh Mahani is a Liberal Studies and English lecturer at the Higher Colleges of Technology in Abu Dhabi, United Arab Emirates. She graduated with a Bachelors degree in Political Science from York University, Canada, a TEFL diploma from the University of Saskatchewan and a Master of Education in Higher Education Leadership from Northcentral University. She is currently a fourth year $\mathrm{PhD}$ student in the School of Education at the Northcentral University in the United States. Her research interests include minority students, first-generation students, globalization of higher education, andragogy and the role of post-secondary institutions and higher education policy in facilitating access for and the success of women in STEM fields. Presently she is leading the development of an Ethical Studies course for EFL learners at Higher Colleges of Technology. She is a member of Association for the Study of Higher Education (ASHE) and Kappa Delta Pi, international honour society.

Arman Molki is a Senior Laboratory Engineer in the department of mechanical engineering at the Petroleum Institute, Abu Dhabi, U.A.E. He has over 10 years of industrial and academic experience in both the United States and the U.A.E. At the Petroleum Institute he oversees the development and operation of the departmental undergraduate laboratories in addition to instructing various laboratory courses. His research interests include the use of technology in engineering education, sensors and instrumentation, data acquisition systems, and computer aided design. He received a B.Sc. degree in computer science with upper level concentration in mathematics from the University of Maryland, College Park. He also holds an M.B.A. in Management of Engineering and Technology and is pursuing a Ph.D. degree in education technology from Northcentral University. Mr. Molki is a member of the American Society of Mechanical Engineers (ASME), Kappa Delta Pi, and Delta Mu Delta.

\section{REFERENCES}

1. Almanac of Higher Education (2010, August 22) Foreign Students' Places of Origins, 2008-9. The Chronicle of Higher Education. Retrieved on January 24, 2011 from http://chronicle.com/article/ChartForeign-Students/123970/

2. Bardsley, D. (2009, May 27). Zayed University to boost numbers. The National. Retrieved January 11, 2011, from http://www.thenational.ae/news/uae-news/education/zayed-university-to-boost-numbers 
3. Bardsley, D. (2008, December 7). Tuition fees checked by universities' expansion. The National. Retrieved February 12, 2011, from http://www.thenational.ae/article/20081207/NATIONAL/640032666/1010.

4. Bardsley, D. (2009, December 24). Universities 'desperate' as funding plan is delayed. The National. Retrieved March 1 2011, from http://www.thenational.ae/apps/pbcs.d11/article?AID=/20091225/NATIONAL/712249867\&SearchID=733 81447367283.

5. $\quad$ Becker, R.F.J. (2009). International branch campuses: markets and strategies. London: The Observatory on Borderless Higher Education.

6. Bitar, A. (2009, June 16) Dubai contributes more than $30 \%$ of the UAE economy. The Gulf News. Retrieved February 11, 2011, from http://gulfnews.com/business/economy/dubai-contributes-more-than30-of-the-uae-economy-1.72289

7. Commission for Academic Accreditation (2011). Retrieved on 2 January 2011 from http://www.caa.ae

8. GMU-RAK. (n.d.). Retrieved February 1, 2011, from http://rak.gmu.edu/

9. Hirschfeld.S., \& Baker, N. (2010, September 23) At the Crossroads: International Programs, Laws, and Cultural Expectations. The Chronicle of Higher Education. Retrieved February 10, 2011, from http://chronicle.com/article/At-the-Crossroads-/124587/

10. Lewin, T. (2008, February 10). U.S. universities rush to set up outposts abroad. The New York Times. Retrieved February 6, 2011, from http://www.nytimes.com/2008/02/10/education/10global.html

11. Lindsey, U. (2011, January 30) A Future Minus Oil. Anticipating the end of their source of wealth, Persian Gulf universities study alternative energy. The Chronicle of Higher Education. Retrieved February 18, 2011, from http://chronicle.com/article/At-Persian-Gulf-Universities/126092/

12. Mills, A. (2010, June 10). Abu Dhabi Proposes Ways to Improve a Higher-Education System That Falls Short. The Chronicle of Higher Education. Retrieved February 18, 2011, from http://chronicle.com/article/Abu-Dhabi-Proposes-Ways-to/65851/

13. Mills, A. (2010, July 19). Why Some Branch Campuses Thrive in the Persian Gulf While Michigan State Pulls Back. The Chronicle of Higher Education. Retrieved February 10, 2011, from http://chronicle.com/article/Why-Some-Branch-Campuses/123612/

14. Moussly, R. (2010, January 3). Universities face shrinking classes. The Gulf News. Retrieved February 26, 2011, from http://gulfnews.com/news/gulf/uae/education/universities-face-shrinking-classes-1.561224.

15. Riley, N.S.,(2010, August 1). The Lure, and the Risks, of Starting a University. The Chronicle of Higher Education. Retrieved February 18, 2011, from http://chronicle.com/article/The-Lurethe-Risks-of/123724/

16. Swan, M. (2011, February 7). Indian University of Pune RAK campus to shut. The National. Retrieved March 1, 2011, from http://www.thenational.ae/news/uae-news/education/indian-university-of-pune-rakcampus-to-shut

17. The Higher Education Landscape in Dubai 2010. (2010). Knowledge and Human Development Authority, Dubai, United Arab Emirates. Retierved April, 1, 2011, from http://www.khda.gov.ae

18. Wildavsky, B (2010, August 26). University Globalization Is Here to Stay. The Chronicle of Higher Education. Retrieved February 28, 2011, from http://chronicle.com/article/University-Globalization$\underline{\text { Is } / 124148 /}$

19. Wilkins, S. (2010). Higher Education in the United Arab Emirates: An Analysis of the Outcomes of Significant Increases in Supply and Competition. Journal of Higher Education Policy \& Management. $32(4), 389-400$. 


\section{NOTES}

